\title{
Investigation of Structural, Magnetic, and Optical Properties of ZnO Codoped with Co and Cd
}

\author{
Lubna Mustafa, ${ }^{1}$ Safia Anjum, ${ }^{1}$ Salma Waseem, ${ }^{1}$ Rehana Zia, ${ }^{1}$ Rameesha Choudhry, \\ Shahid M. Ramay, ${ }^{2}$ Asif Mahmood, ${ }^{3}$ Shahid Atiq, ${ }^{4}$ and Salah Ud-Din Khan ${ }^{5}$ \\ ${ }^{1}$ Department of Physics, Lahore College for Women University, Lahore 54600, Pakistan \\ ${ }^{2}$ Physics and Astronomy Department, College of Science, King Saud University, P.O. Box 800, Riyadh 11421, Saudi Arabia \\ ${ }^{3}$ Department of Chemical Engineering, College of Engineering, King Saud University, P.O. Box 800, Riyadh 11421, Saudi Arabia \\ ${ }^{4}$ Centre of Excellence in Solid State Physics, University of the Punjab, Quaid-e-Azam Campus, Lahore 54590, Pakistan \\ ${ }^{5}$ Sustainable Energy Technologies Center, King Saud University, Riyadh 11421, Saudi Arabia
}

Correspondence should be addressed to Lubna Mustafa; lubnamustafa@hotmail.com

Received 6 May 2014; Revised 17 September 2014; Accepted 9 October 2014; Published 24 November 2014

Academic Editor: Da-Ren Hang

Copyright (C) 2014 Lubna Mustafa et al. This is an open access article distributed under the Creative Commons Attribution License, which permits unrestricted use, distribution, and reproduction in any medium, provided the original work is properly cited.

\begin{abstract}
$\mathrm{Co}$ and $\mathrm{Cd}$ have been codoped in $\mathrm{ZnO}$ using a simple solid state reaction technique to synthesize dilute magnetic oxide semiconductors of composition $\mathrm{Zn}_{0.9} \mathrm{Co}_{0.1-x} \mathrm{Cd}_{x} \mathrm{O}(x=0.0-0.1$ with an increment of 0.02). Hexagonal wurtzite structure has been obtained for samples up to $x=0.06$, using X-ray diffractometry. However, at $x=0.08$ and 0.1 , secondary peak of CdO is observed. Raman spectra of the samples have been obtained in $200-800 \mathrm{~cm}^{-1}$ range. UV-VIS spectrophotometer is used to study the optical properties, which shows that band gap energy decreases with the increase in Cd concentration. A weak ferromagnetic behavior was evident which decreased further by adding $\mathrm{Cd}$ in the series. Room temperature resistivity measurements performed using fourpoint probe technique showed that their values lie in the semiconductor range. Structural morphology of the samples has been investigated by a scanning electron microscope and grain size has been determined. Raman spectra and Fourier transform infrared spectroscopy revealed the successful incorporation of $\mathrm{Co}$ and $\mathrm{Cd}$ ions into the host $\mathrm{ZnO}$ lattice.
\end{abstract}

\section{Introduction}

Dilute magnetic oxide semiconductors (DMS) are a class of materials in which a fraction of ions are magnetic. The main concern in magnetic semiconductor research is the interaction between semiconductor band electrons (e.g., charge carriers or impurity states) and magnetic moments of the ions. This interaction results in a range of electronic phenomena, such as giant magnetoresistance, strong magnetooptical rotation, magnetically driven semiconductor-metal transition, and magnetic polaron effects. The presence of semiconducting and magnetic properties in these compounds and the ability to independently control them offer the possibilities for a number of technological and scientific opportunities $[1,2]$. The magnetic interactions in II-VI DMSs, for example, in $\mathrm{ZnO}$, are dominated by antiferromagnetic exchange among the spins of a proper dopant, which results in the paramagnetic, antiferromagnetic, or spin-glass behavior of the materials $[3,4]$. Ferromagnetism in codoped $\mathrm{ZnO}$ was first found by Ueda et al. [5] in thin films. A few research groups have fabricated bulk samples of $\mathrm{Mn}$ and Co doped $\mathrm{ZnO}$ by different synthesis routes. It is observed that, with low concentration of $\mathrm{Co}$, material is paramagnetic. At 5 at\%, some secondary phases were witnessed and were suggested as a source of magnetism [6]. ZnO doped with $\mathrm{Ni}$ showed super paramagnetic behavior at $300 \mathrm{~K}$ and charge carriers mediated ferromagnetic state was established at $2 \mathrm{~K}$ [7]. Nevertheless, room temperature ferromagnetism in $\mathrm{Zn}_{1-x} \mathrm{M}_{x} \mathrm{O}(\mathrm{M}=\mathrm{Co}$, $\mathrm{Ni}, \mathrm{Fe}$ ) is still controversial, because of contradictory reports from many experimental studies [8].

Donor states are produced by intrinsic defects in $\mathrm{ZnO}$ as it has been observed that $(\mathrm{Zn}, \mathrm{Ni}) \mathrm{O},(\mathrm{Zn}, \mathrm{Fe}) \mathrm{O}$, and $(\mathrm{Zn}$, Co)O show ferromagnetism with a Curie temperature $\left(T_{c}\right)$ in the absence of carrier concentration [9]. The addition of 
carriers in doped $\mathrm{ZnO}$ is found to increase this ferromagnetic behavior. Appearance of secondary phases at high dopant concentration and high annealing temperature motivated the researchers towards simultaneous doping of two or more transition metal ions in $\mathrm{ZnO}$ [10]. The above discussion led the present work to explore the characteristic properties of $\mathrm{Co}$ and $\mathrm{Cd}$ codoped $\mathrm{ZnO}$ based DMS materials.

In this paper, we present the synthesis of dilute magnetic oxide semiconductors with composition $\mathrm{Zn}_{0.9} \mathrm{Co}_{0.1-x} \mathrm{Cd}_{x} \mathrm{O}$ ( $x=0.0-0.1$ by an increment of 0.02) using a simple and low cast solid state reaction method. The effect of Co and Cd codoping on the structural, magnetic, and optical response of $\mathrm{ZnO}$ has been investigated.

\section{Materials and Methods}

A series of six samples having general formula $\mathrm{Zn}_{0.9} \mathrm{Co}_{0.1-x} \mathrm{Cd}_{x} \mathrm{O}(x=0.0,0.02,0.04,0.06,0.08 \& 1.0$ ) were prepared by solid state reaction method. This method has been adopted due to its simplicity and economical value. In addition, it allows chemical reactions without the need of solvents. Stoichiometric amounts of analytical grade reagents like $\mathrm{ZnO}, \mathrm{CoO}$, and $\mathrm{CdO}$ were separately weighed using a precise electronic balance. The oxide powders were mixed and milled using a ball milling machine for 45 minutes. After sieving, calcination of the raw samples was carried out at $850^{\circ} \mathrm{C}$ for $16 \mathrm{~h}$ in high temperature furnace.

The resultant samples were characterized for structural properties using D-8 Discover X-ray diffractometer (XRD). Raman spectroscopy and MIDAC 2000 (USA) Fourier transform infrared spectroscopy (FTIR) were performed to determine the incorporation of dopants in the host matrix. The FTIR spectroscopy was performed using background subtractor scan range of 400-4500 with wavelength range of 300-900 nm. UV-visible spectrometry (UV-VIS, UV2800, Hitachi, Japan) was employed to find the optical band gap of the samples. Structural morphology was investigated using a S-3400N Hitachi scanning electron microscope (SEM). Magnetic properties were determined using a Lakeshore 7436 vibrating sample magnetometer (VSM).

\section{Results and Discussion}

Crystal structure of the samples has been investigated by XRD using $\mathrm{Cu} K_{\alpha}$ radiations with $\lambda=0.154 \mathrm{~nm}$. Figure 1 shows diffraction patterns of $\mathrm{Zn}_{0.9} \mathrm{Co}_{0.1-x} \mathrm{Cd}_{x} \mathrm{O}(x=0.0$, $0.02,0.04,0.06,0.08$, and 0.1$)$. The patterns reveal that the samples below $x=0.06$ consist of hexagonal wurtzite structure, as all the peaks were matched with the standard JCPD card, characteristic of $\mathrm{ZnO}$ structure. As the doping concentration of $\mathrm{Cd}$ was raised to $6 \%$, some impurity peaks began to peep. The intensity of these impurity peaks became significant as the doping concentration was raised above $6 \%$. These peaks were identified as belonging to $\mathrm{CdO}$, one of the reactants. The possible reason might be attributed to its excess value and/or insufficient reaction temperature. The most intense diffraction peak was utilized to find various structural

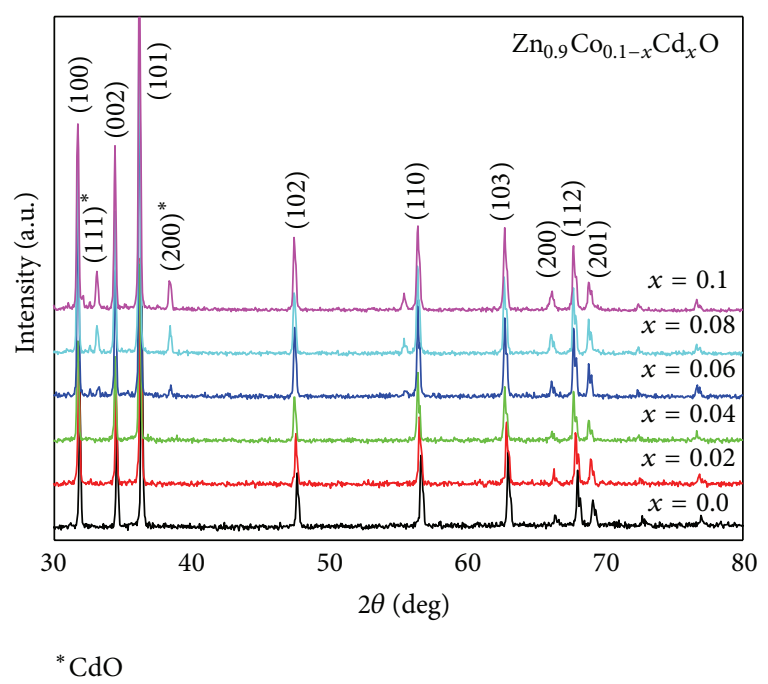

FIGURE 1: XRD pattern of $\mathrm{Zn}_{0.9} \mathrm{Co}_{0.1-x} \mathrm{Cd}_{x} \mathrm{O}(x=0.0,0.02,0.04$, $0.06,0.08$, and 0.1 .

parameters. Lattice parameters $a$ and $c$ were determined manually by using

$$
\sin ^{2} \theta=\frac{\lambda^{2}}{4 a^{2}}\left[\frac{4}{3}\left(h^{2}+h k+k^{2}\right)+\frac{l^{2}}{(c / a)^{2}}\right],
$$

where $d$ is the interplanar distance and $h k l$ are the miller indices of the corresponding plane. It was found that $a$ and $c$ increased with the increase in the Cd concentration in the series. This increase could be attributed to the larger ionic radius of $\mathrm{Cd}^{2+}$ as compared to $\mathrm{Co}^{2+}$.

The crystallite size has been calculated by Scherrer's formula [11], given as

$$
D=\frac{k \lambda}{B \cos \theta}
$$

where $B$ is the full width at half maximum (FWHM) in radians, $\theta$ is Bragg's angle, $\lambda$ represents the wavelength $(\lambda=$ $0.154 \mathrm{~nm}$ ) of $\mathrm{Cu} K_{\alpha}$ radiation, and " $D$ " is the crystallite size. The evaluated crystalline sizes were in 70-100 $\mathrm{nm}$ range.

Raman spectroscopy of $\mathrm{Zn}_{0.9} \mathrm{Co}_{0.1-x} \mathrm{Cd}_{x} \mathrm{O}(x=0.0,0.02$, $0.04,0.06$, and 0.08 ) samples in the range $200-800 \mathrm{~cm}^{-1}$ is shown in Figure 2. All the labeled modes belong to $\mathrm{ZnO}$. The main dominant peak $\left(\mathrm{E}_{2}\right)$ is found in the range $430-$ $433 \mathrm{~cm}^{-1}$ for all samples. Theoretically calculated value of $\mathrm{E}_{2}$ is $436 \mathrm{~cm}^{-1}$ called Raman optical active phonon mode, characteristic of wurtzite hexagonal phase, also associated with $\mathrm{ZnO}$ structure. $\mathrm{E}_{2}$ values slightly shift towards lower frequency side. This shift may be due to structural disorder because of secondary peaks and different ionic radii of Co and Cd dopants [12].

FTIR is a technique used to obtain information about the chemical bonding in a material. Figure 3 shows comparative FTIR spectra of all the six samples. Distinct absorption peak around $468.9 \mathrm{~cm}^{-1}$ for all the samples represents stretching bond for $\mathrm{Zn}-\mathrm{O}$ mode [13]. The peak at $1651 \mathrm{~cm}^{-1}$ is due 


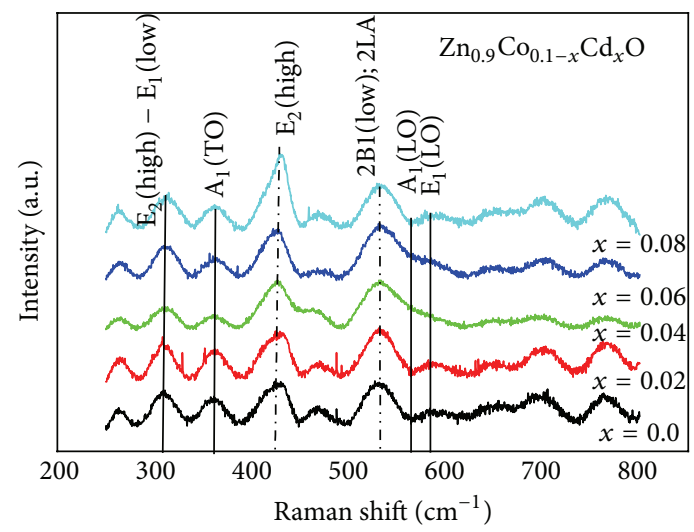

FIGURE 2: Raman spectra of $\mathrm{Zn}_{0.9} \mathrm{Co}_{0.1-x} \mathrm{Cd}_{x} \mathrm{O}(x=0.0,0.02,0.04$, 0.06 , and 0.08 ).

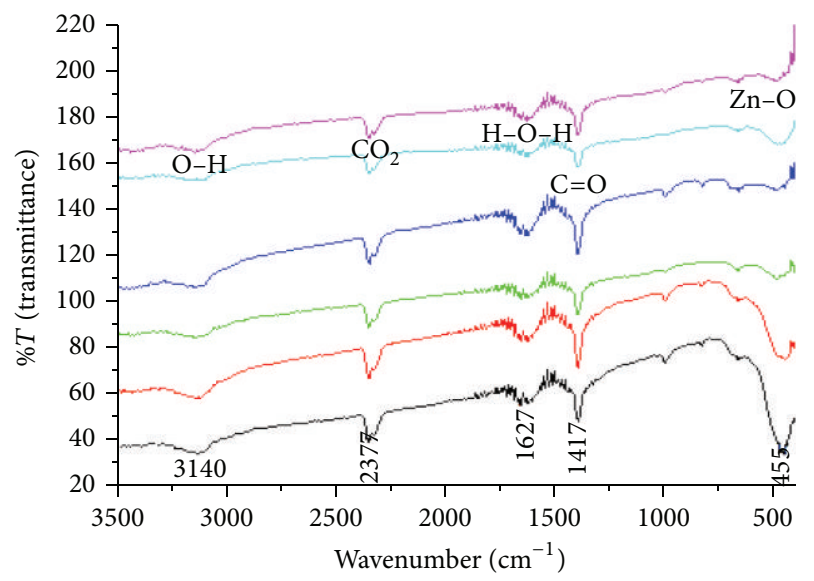

FIGURE 3: FTIR spectra of $\mathrm{Zn}_{0.9} \mathrm{Co}_{0.1-x} \mathrm{Cd}_{x} \mathrm{O}(x=0.0,0.02,0.04$, $0.06,0.08$, and 0.1$)$.

to water molecules in $\mathrm{KBr}$, which has been used in the preparation of samples for FTIR analysis. A small absorption peak observed around $2436-2438 \mathrm{~cm}^{-1}$ is due to the existence of $\mathrm{CO}_{2}$ molecule in air. The broad absorption peaks centered at $3467 \mathrm{~cm}^{-1}$ are attributed to $\mathrm{O}-\mathrm{H}$ stretching vibration of $\mathrm{H}_{2} \mathrm{O}$ in $\mathrm{Zn}-\mathrm{O}$ lattice. The gradual shift in the absorption frequency is due to the different bond lengths that occur when $\mathrm{Co}^{2+}$ and $\mathrm{Cd}^{2+}$ ions replace $\mathrm{Zn}^{2+}$ ions. This assures the integration of $\mathrm{Co}$ and $\mathrm{Cd}$ ions into $\mathrm{ZnO}$ lattice.

UV-visible spectroscopy technique determines the absorbance, reflectance, and transmission through a sample. The absorption spectra help us find the band gap, which is an important characteristic of a semiconductor. Direct band gap energy " $E_{g}$ " is calculated by using Tauc's equation, given as

$$
(\alpha h v)^{2}=B\left(h v-E_{g}\right)
$$

Here, " $B$ " is a constant known as band tailing parameter. The band gap values are calculated by plotting graph of $(\alpha h \nu)^{2}$ versus $h v$ and extrapolating straight line down to $(\alpha h \nu)^{2}=0$, as shown in Figure 4 . The band gap value of $10 \%$ Co doped
TABLE 1: Band gap energy, magnetization, and coercivity of $\mathrm{Zn}_{0.9} \mathrm{Co}_{0.1-x} \mathrm{Cd}_{x} \mathrm{O}(x=0.0,0.02,0.04,0.06,0.08$, and 0.1$)$.

\begin{tabular}{lccc}
\hline Samples & $\begin{array}{c}\text { Band gap } \\
(\mathrm{eV})\end{array}$ & $\begin{array}{c}\text { Magnetization } \\
\text { (emu/g) } \\
\times 10^{-1}\end{array}$ & $\begin{array}{c}\text { Coercivity } H_{c} \\
(\mathrm{Oe})\end{array}$ \\
\hline$x=0.0$ & 3.74 & 3.90 & 46.09 \\
$x=0.02$ & 3.71 & 1.60 & 2.915 \\
$x=0.04$ & 2.83 & 1.22 & 2.739 \\
$x=0.06$ & 2.63 & 0.65 & 2.683 \\
$x=0.08$ & 2.45 & 0.42 & 2.915 \\
$x=0.1$ & 2.38 & 0.15 & 8.335 \\
\hline
\end{tabular}

sample was found to be $3.73 \mathrm{eV}$, which was more than that of pure $\mathrm{ZnO}$, in accordance with some recent results $[14,15]$. Band gap values of $\mathrm{Zn}_{0.9} \mathrm{Co}_{0.1-x} \mathrm{Cd}_{x} \mathrm{O}(x=0.00,0.04,0.06$, $0.08 \& 0.10)$ shift to the lower energy from 3.73 to $2.37 \mathrm{eV}$, as listed in Table 1. The red shift shows that the dopants have successfully blended into the lattice of $\mathrm{ZnO}$. The sp-d exchange interaction between band electrons and delectrons of $\mathrm{Co}^{2+}$ and $\mathrm{Cd}^{2+}$ ions that are substituting $\mathrm{Zn}^{2+}$ ions causes the narrowing of band gaps. It has been understood that, with the increased concentration of dopant species, energy levels or overlapping orbitals increases and width of the band starts to increase, which cause a decrease in the band gap energy.

The effect of various dopants to decrease the optical band gap has been explained by many groups who have suggested the alloying effect in the host compound and the presence of some impurity phases as the main cause to affect $E_{g}[16]$.

Surface morphology of prepared samples was studied by SEM. Representative SEM micrographs of $\mathrm{Zn}_{0.9} \mathrm{Co}_{0.1-x} \mathrm{Cd}_{x} \mathrm{O}$ $(x=0.0,0.04 \& 0.1)$ and EDX spectra of $\mathrm{Zn}_{0.9} \mathrm{Co}_{0.06} \mathrm{Cd}_{0.04} \mathrm{O}$ have been shown in Figure 5. The micrographs show high crystallinity of samples because of development of grains with well-defined boundaries. The size of grains, determined by line intercept method, was found to increase from $0.3 \mu \mathrm{m}$ to $0.7 \mu \mathrm{m}$ in the series of samples. The EDX spectra confirmed the stoichiometric at $\%$ and $w t \%$ of all the elements in the samples in accordance with the theoretical calculations, as revealed by the representative spectra of sample $\mathrm{Zn}_{0.9} \mathrm{Co}_{0.06} \mathrm{Ni}_{0.04} \mathrm{O}$ shown in Figure 5(d).

The magnetic properties of all the samples were studied using VSM at room temperature. The magnetic hysteresis $(M-H)$ loops of first three samples are shown in Figure 6 and the last three are shown in Figure 7, displaying a weak ferromagnetic behavior. In the sample $x=0.0$, the value of magnetization $(M)$ is maximum $(0.390 \mathrm{emu} / \mathrm{g})$. This is because maximum Co spins are ferromagnetically (FM) coupled and few are antiferromagnetically coupled or uncoupled [17]. As concentration of Cd increases, magnetization decreases and becomes lowest $(0.015 \mathrm{emu} / \mathrm{g})$ at $x=0.1$. This is because FM coupling between $\mathrm{Co}^{2+} \cdot \mathrm{Co}^{2+}$ ions decreases by the addition of $\mathrm{Cd}^{2+}$ into the material, since all the $d$ shell of Cd is fully occupied. Furthermore, when Cd is added into the material the lattice parameter $a$ increases due to larger ionic radii of $\mathrm{Cd}$, and magnetization shows a sensitive behavior to such changes [18]. An increase in 


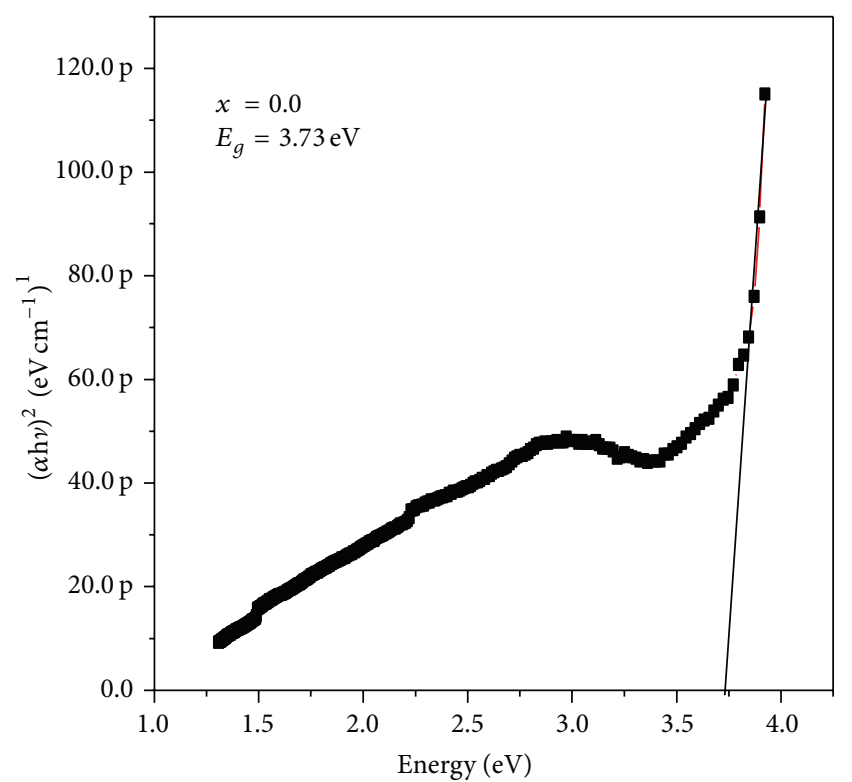

(a)

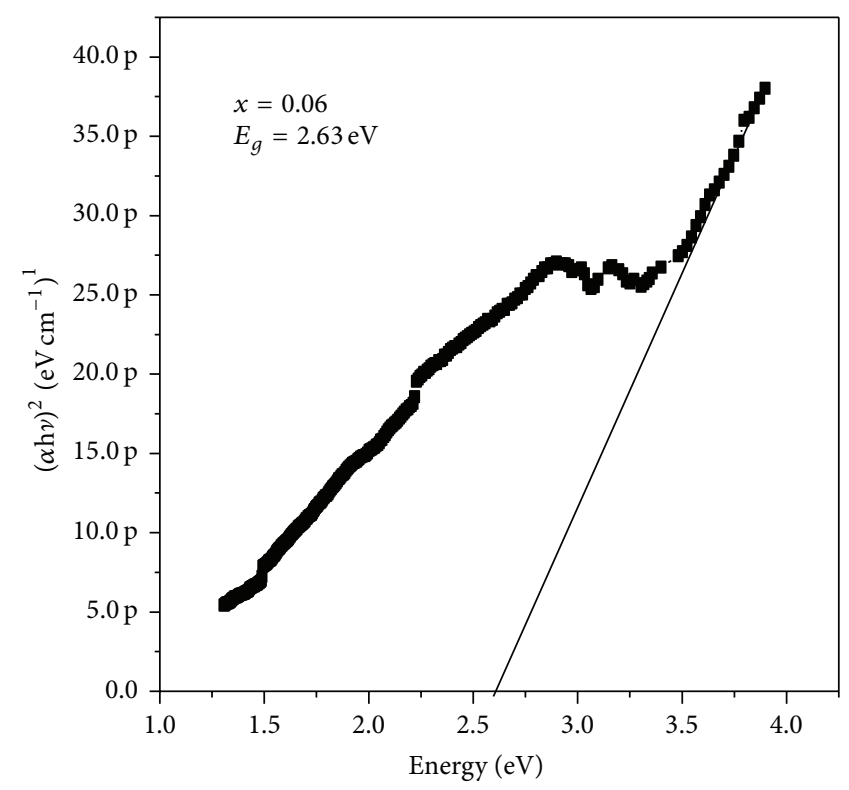

(b)

FIgUre 4: Plot of $(\alpha h v)^{2}$ versus energy of (a) $\mathrm{Zn}_{0.9} \mathrm{Co}_{0.1} \mathrm{Cd}_{0.0} \mathrm{O}$ and (b) $\mathrm{Zn}_{0.9} \mathrm{Co}_{0.04} \mathrm{Cd}_{0.06} \mathrm{O}$.

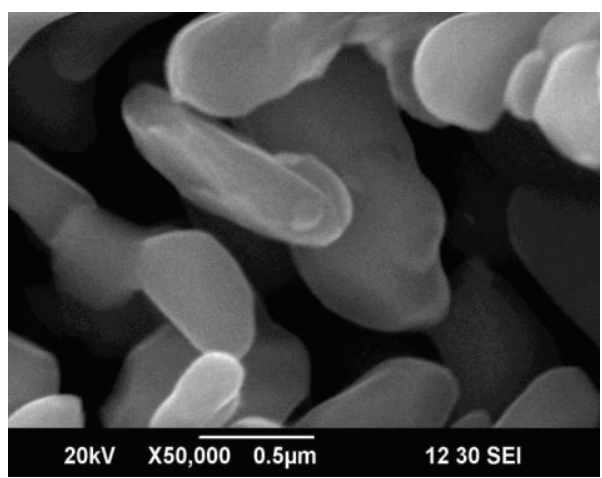

(a)

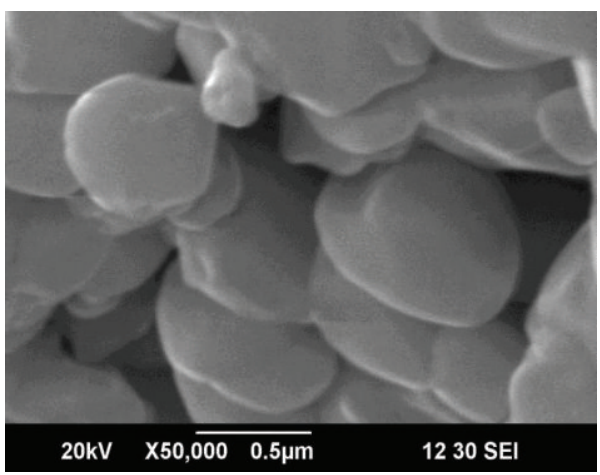

(c)

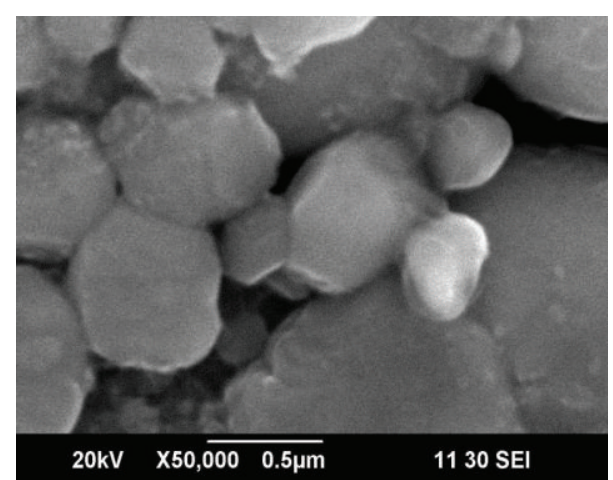

(b)

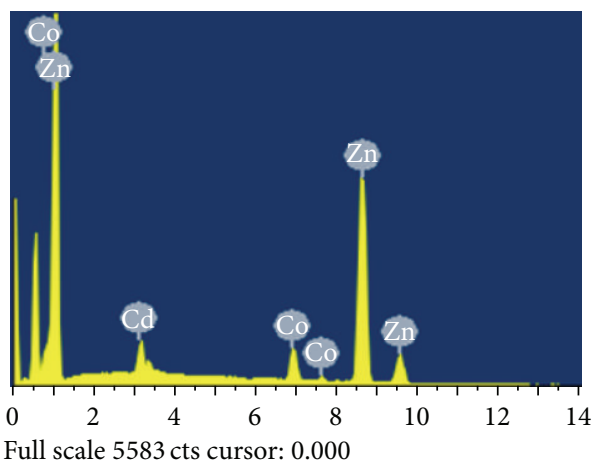

(d)

Figure 5: SEM micrographs of (a) $\mathrm{Zn}_{0.9} \mathrm{Co}_{0.1} \mathrm{O}$, (b) $\mathrm{Zn}_{0.9} \mathrm{Co}_{0.06} \mathrm{Cd}_{0.04} \mathrm{O}$, (c) $\mathrm{Zn}_{0.9} \mathrm{Cd}_{0.1} \mathrm{O}$, and (d) $\mathrm{EDX}$ of $\mathrm{Zn}_{0.9} \mathrm{Co}_{0.06} \mathrm{Cd}_{0.04} \mathrm{O}$.

lattice parameter shows greater (Co, Cd... Co, Cd) distances, which will ultimately influence their magnetic interactions and cause lowering of magnetization.

The development of secondary phase is also considered as source of magnetization in DMS materials. In the present case, from $x \geq 0.06$, a secondary phase of $\mathrm{CdO}$ has been observed. However, this phase could not contribute towards magnetization as it decreased with increased $\mathrm{CdO}$ contents in the samples. Higher carrier concentration induces magnetization but the resistivity of our samples is found to 


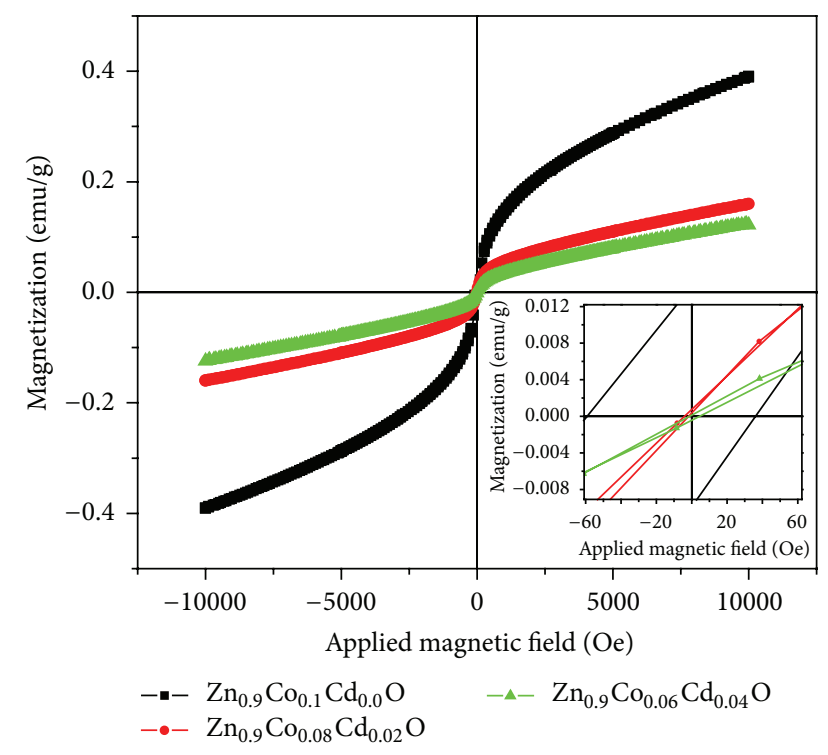

Figure 6: $M-H$ loop of $\mathrm{Zn}_{0.9} \mathrm{Co}_{0.1-x} \mathrm{Cd}_{x} \mathrm{O}(x=0.0,0.02$, and 0.04$)$. The inset shows corresponding magnified loops.

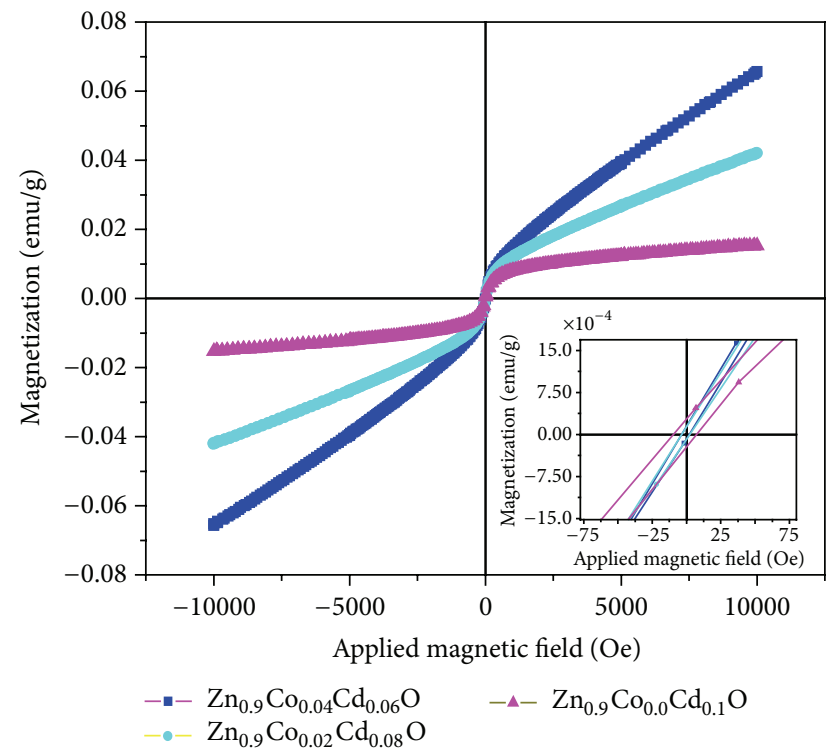

Figure 7: $M-H$ loop of $\mathrm{Zn}_{0.9} \mathrm{Co}_{0.1-x} \mathrm{Cd}_{x} \mathrm{O}(x=0.06,0.08$, and 0.1$)$. The inset shows corresponding magnified loops.

be of the order of $10^{8}-10^{9} \Omega-\mathrm{m}$. This indicates low carrier concentration, so the carrier induced magnetization cannot be considered here.

The value of coercivity decreased from 46.1 Oe to 8.34 Oe in the series, listed in Table 1 , as grain size increases from $0.3 \mu \mathrm{m}$ to $0.7 \mu \mathrm{m}$. It is due to the fact that large grain size produces less grain boundaries which are magnetically isolated from neighboring grains and it requires lesser magnetizing force for magnetization.

\section{Conclusions}

A series of $\mathrm{Zn}_{0.9} \mathrm{Co}_{0.1-x} \mathrm{Cd}_{x} \mathrm{O}(x=0.00,0.02,0.04,0.06$, 0.08 , and 0.10 ) samples was synthesized by solid state reaction method. The samples up to $x=0.06$ exhibit hexagonal wurtzite structure same as that of host material. The main dominant peak around $430-433 \mathrm{~cm}^{-1}$ corresponds to hexagonal wurtzite structure found by Raman spectra. The absorption peak around $468.9 \mathrm{~cm}^{-1}$ for all the samples represents stretching bond for $\mathrm{Zn}-\mathrm{O}$ mode. A weak ferromagnetic behavior was observed in the samples, but the saturation value of magnetization could not be attained. Synthesized samples possess optimum semiconducting and magnetic characteristics that could be exploited for potential spintronic applications.

\section{Conflict of Interests}

The authors declare that there is no conflict of interests regarding the publication of this paper.

\section{Acknowledgment}

The authors wish to acknowledge the Deanship of Scientific Research at King Saud University for funding the work partially through the research group Project no. RGP-VPP311.

\section{References}

[1] J. K. Furdyna, Diluted Magnetic Semiconductors, National Academy Press, Washington, DC, USA, 1991.

[2] M. S. Anwar, F. Ahmed, S. N. Heo, K. Y. Park, and B. H. Koo, "Indication of room temperature ferromagnetism in highly transparent and conductive Ga-doped $\mathrm{SnO}_{2}$ thin films," Thin Solid Films, vol. 547, pp. 137-140, 2013.

[3] M. Agrawal, Magnetic properties of materials, dilute magnetic semiconductors, magnetic resonances and spintronics [Ph.D. thesis], 2003.

[4] A. Haury, A. Wasiela, A. Arnoult et al., "Observation of a ferromagnetic transition induced by two-dimensional hole Gas in modulation-doped CdMnTe quantum wells," Physical Review Letters, vol. 79, no. 3, pp. 511-514, 1997.

[5] K. Ueda, H. Tabata, and T. Kawai, "Magnetic and electric properties of transition-metal-doped $\mathrm{ZnO}$ films," Applied Physics Letters, vol. 79, no. 7, 2001.

[6] L. Yan, C. K. Ong, and X. S. Rao, "Magnetic order in Co-doped and $(\mathrm{Mn}, \mathrm{Co})$ codoped $\mathrm{ZnO}$ thin films by pulsed laser deposition," Journal of Applied Physics, vol. 96, no. 1, pp. 508-511, 2004.

[7] T. Wakano, N. Fujimura, Y. Morinaga, N. Abe, A. Ashida, and T. Ito, "Magnetic and magneto-transport properties of $\mathrm{ZnO}: \mathrm{Ni}$ films," Physica E, vol. 10, no. 1-3, pp. 260-264, 2001.

[8] F. Ahmed, S. Kumar, N. Arshi, M. S. Anwar, B. H. Koo, and C. G. Lee, "Doping effects of $\mathrm{Co}^{2+}$ ions on structural and magnetic properties of $\mathrm{ZnO}$ nanoparticles," Microelectronic Engineering, vol. 89, no. 1, pp. 129-132, 2012.

[9] G. Lawes, A. S. Risbud, A. P. Ramirez, and R. Seshadri, "Absence of ferromagnetism in Co and $\mathrm{Mn}$ substituted polycrystalline ZnO," Physical Review B: Condensed Matter and Materials Physics, vol. 71, no. 4, Article ID 045201, 5 pages, 2005. 
[10] K. C. Sebastian, M. Chawda, L. Jonny, and D. Bodas, "Structural, magnetic and optical studies of $\left(\mathrm{Zn}_{0.90} \mathrm{Co}_{0.05} \mathrm{Ni}_{0.05} \mathrm{O}\right) \mathrm{DMS}$," Materials Letters, vol. 64, no. 20, pp. 2269-2272, 2010.

[11] C. Koch, I. Ovid'ko, S. Seal, and S. Veprek, Structural Nanocrystalline Materials: Fundamentals and Applications, Cambridge University Press, 2007.

[12] B.-B. Li, X.-Q. Xiu, R. Zhang et al., "Analysis of local structures around $\mathrm{Ni}$ atoms doped in $\mathrm{ZnO}$-based diluted magnetic semiconductors by fluorescence EXAFS," Chinese Physics Letters, vol. 23, no. 4, pp. 907-910, 2006.

[13] R. N. Aljawfi and S. Mollah, "Properties of $\mathrm{Co} / \mathrm{Ni}$ codoped $\mathrm{ZnO}$ based nanocrystalline DMS," Journal of Magnetism and Magnetic Materials, vol. 323, no. 23, pp. 3126-3132, 2011.

[14] D. P. Joseph and C. Venkateshwaran, "Bandgap engineering in $\mathrm{ZnO}$ by doping with $3 \mathrm{~d}$ transition metal ions," Journal of Atomic, Molecular, and Optical Physics, vol. 2011, Article ID 270540, 7 pages, 2011.

[15] A. Kaushik, B. Dalela, R. Rathore et al., "Influence of Co doping on the structural, optical and magnetic properties of $\mathrm{ZnO}$ nanocrystals," Journal of Alloys and Compounds, vol. 578, pp. 328335, 2013.

[16] M. Kuppan, S. Kaleemulla, N. M. Rao, N. Sai Krishna, M. R. Begam, and M. Shobana, "Structural and magnetic properties of Ni doped $\mathrm{SnO}_{2}$," Advances in Condensed Matter Physics, vol. 2014, Article ID 284237, 5 pages, 2014.

[17] Z. M. Tian, S. L. Yuan, J. H. He et al., "Structure and magnetic properties in $\mathrm{Mn}$ doped $\mathrm{SnO}_{2}$ nanoparticles synthesized by chemical co-precipitation method," Journal of Alloys and Compounds, vol. 466, no. 1-2, pp. 26-30, 2008.

[18] C. Gao, F. Lin, X. Zhou, W. Shi, and A. Liu, "Fe concentration dependences of microstructure and magnetic properties for $\mathrm{Cu}\left(\mathrm{Cr}_{1-x} \mathrm{Fe}_{x}\right) \mathrm{O}_{2}$ ceramics," Journal of Alloys and Compounds, vol. 565, pp. 154-158, 2013. 

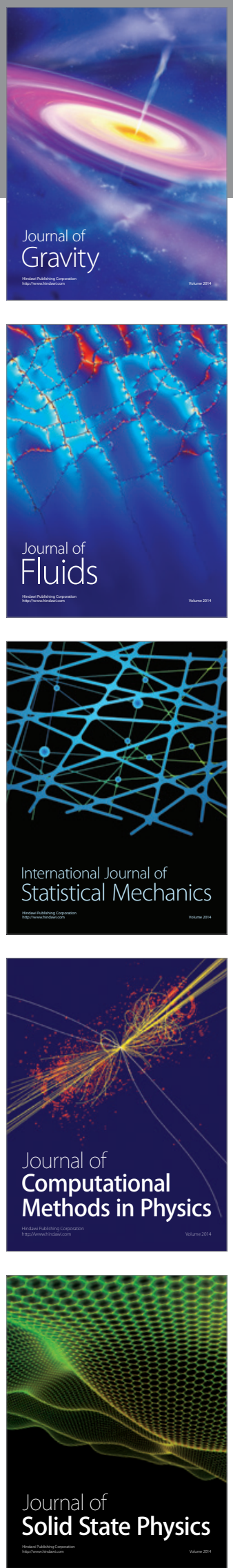

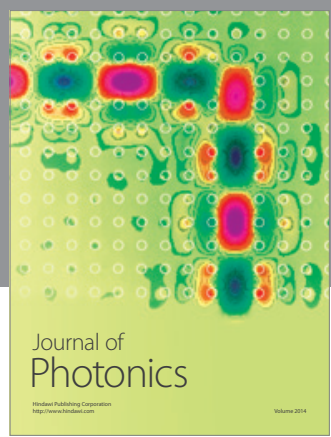

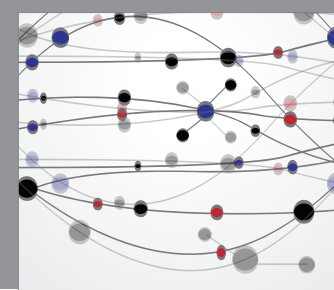

The Scientific World Journal

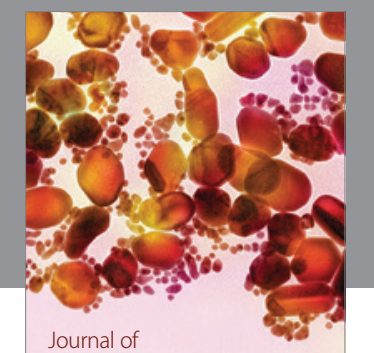

Soft Matter
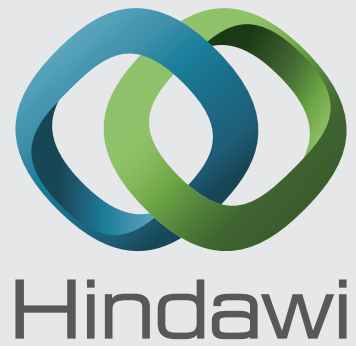

Submit your manuscripts at

http://www.hindawi.com
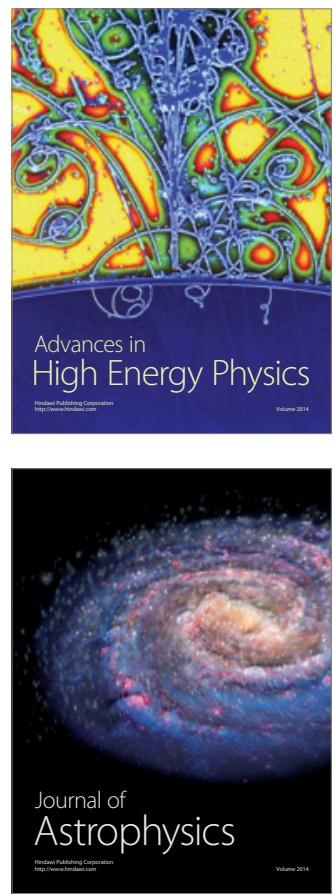
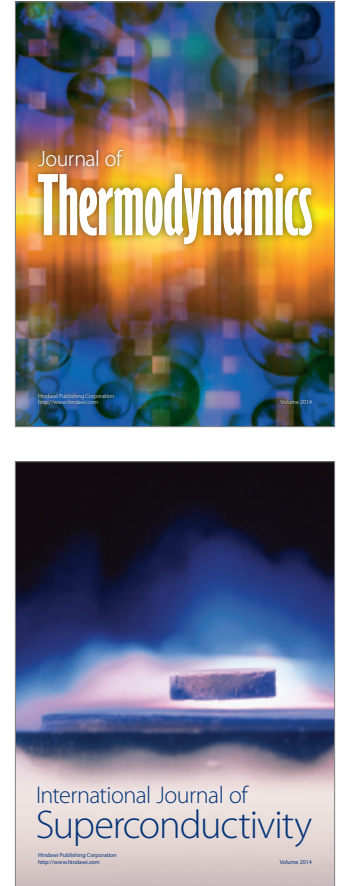
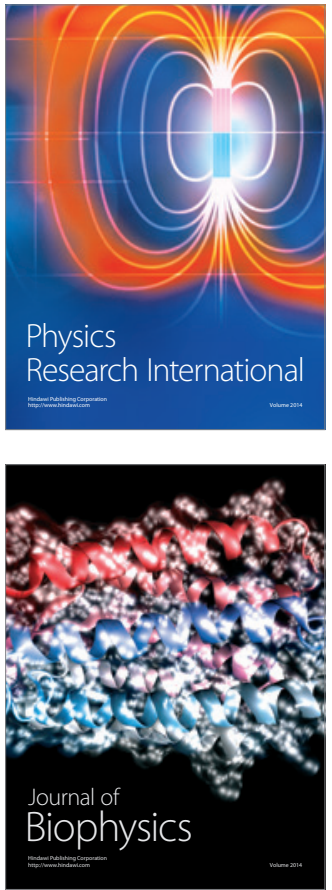
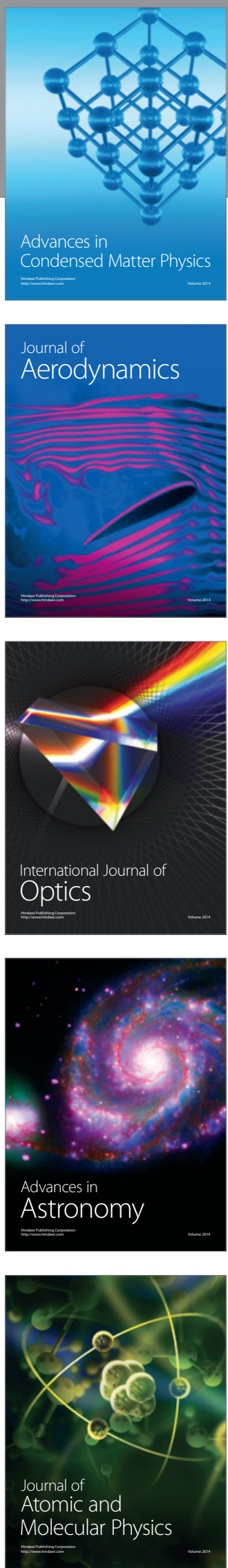